\title{
Synergy of fuzzy AHP and Six Sigma for capacity waste management in Indian automotive industry
}

\author{
Rajeev Rathi ${ }^{\mathrm{a}^{*}}$, Dinesh Khanduja ${ }^{\mathrm{b}}$ and S.K. Sharma ${ }^{\mathrm{c}}$
}

${ }^{a}$ Research Scholar, Department of Mechanical Engineering, National Institute of Technology, Kurukshetra, Haryana, India, 136119

${ }^{b}$ Professor, Department of Mechanical Engineering, National Institute of Technology, Kurukshetra, Haryana, India, 136119

${ }^{c}$ Former Professor, Department of Mechanical Engineering, National Institute of Technology, Kurukshetra, Haryana, India, 136119

\begin{tabular}{l}
\hline C H R O N I C L E \\
\hline Article history: \\
Received December 10, 2014 \\
Received in revised format: \\
January 4, 2015 \\
Accepted February 5, 2015 \\
Available online \\
February 9 2015 \\
\hline Keywords: \\
Capacity waste \\
Six Sigma \\
Analytical hierarchy process \\
Fuzzy logic \\
Centre less grinding \\
MADM
\end{tabular}

\section{Introduction}

The evaluation of capacity waste owes its importance to the fact that, if properly managed, it may provide a consistent indication of early intensification in an industry. The term industrial capacity is subject to several interpretations but in practice, the three concepts are widely used and these areDesign Capacity, Effective Capacity and Actual Capacity. Design capacity is maximum rate of output that might be achieved under almost ideal conditions and effective capacity is planned after compensating for certain essential unavoidable delays. Despite the best efforts on the part of management, effective capacity is never achieved and the actual output is obtained is determined by the occurrence of casual delays which are basically due to deficiencies, inadequacies and fallacies on the part of workers as well as management. These measures of capacity are useful in defining Capacity

\begin{abstract}
Capacity waste management is highly essential because under utilization of capacity is often referred to as a major reason for lower productivity among industries around the world. For better estimation of capacity and its utilization and then for its improved management; newer techniques are being devised in industrial sector. The current case of capacity waste problem has been taken up as a Six Sigma project, where we try to analyze critical factors responsible for the capacity waste. Decisions on critical factor selection in analysis phase of Six Sigma are always very crucial. The paper discusses an approach for selection of capacity waste factors at an automotive industry using fuzzy logic based AHP method. The fuzzy AHP is a well the different decision variables engaged in the process of capacity waste factors selection. In this context, we have explored six crucial parameters for selection of capacity waste factors. Final ranking is calculated through priority vector thus obtained and it is seen that conveyor malfunction is found to be the key factor for capacity waste among all alternatives at the selected site.
\end{abstract}

(C) 2015 Growing Science Ltd. All rights reserved.

* Corresponding author. Tel: +91-1744-233455, mob: +91-9996886672

E-mail address: rajeevrathi_1443@nitkkr.ac.in (R. Rathi) 
Utilization (CU). CU is the ratio of Actual capacity to Design capacity.

$$
\begin{aligned}
& C U=\frac{\text { Actual Capacity }}{\text { Design Capacity }} \\
& \text { So Capacity Waste }=1-C U
\end{aligned}
$$

Capacity of a facility can be defined as the total productive capability of all the utilized productive resources including workforce and machinery to produce an output over a period of time. The capacity however is subjected to intensiveness of use of the facilities. It is possible to enhance capacity by working for more days or more hours or by acquiring internal or external contingent resources (Alp \& Tan, 2008). Temporarily capacity can be increased to meet additional demand by these methods. If we want to upgrade the capacity we can do so by balancing equipment to create a better balance amongst the sub processes and through proper capacity waste management like by reducing down time in the pant. Capacity management in the manufacturing decision making process is linked to production planning and control, quality control, assurance, plant and equipment (Orr, 1999). Capacity is generally provide the means for producing a product or service (Hammesfahr et al., 1993). Capacity waste level in the industries gives information on the level of resource utilization in the nation which may in turn provide information on the expected future way of inflation (Baghestani, 2008). The CU measure facilitates an industry to know the extent of waste capacities available, and the differences in the degree of CU among firms (Sahoo \& Tone, 2009). Capacity management is desirable because under utilization is often referred as a major reason for lower productivity of industries around the world. Better estimates of capacity and its utilization and improved management techniques are necessary that lower the rate of capacity waste and lessen the effect of under utilization (Felthoven et al., 2009).

This serious problem of capacity waste of automotive industry in our case study has been taken up through Six Sigma project. In this context, Six Sigma is highly efficient process that focuses on developing and delivering stable product, process and services in a consistent way (Eckes, 2002). It is a highly established approach that aims to recognize and eliminate defects, faults or breakdowns, reduces cycle times, decreases inventory, increases productivity, decreases work-in-progress, improves capacity and output, increases quality and reliability, higher levels of satisfaction and decreases unit costs in processes or systems by centring on those process performance parameters that are of critical importance to success (Coronado \& Antony, 2002; Snee, 2004). Six Sigma emerging as a powerful strategy has been well recognised as an imperative for achieving and sustaining business excellence in operation and services both. It has evolved as a disciplined, data-driven process and quality improvement approach in many organisations worldwide. It is highly disciplined and statistically based approach for removing defects from products, processes, and business involving everybody in the corporation (Antony, 2004; Antony \& Fergusson, 2004; Dedhia, 2005; Hahn et al., 1999).The statistical concept of Six Sigma means that processes are working near to perfection, carrying only 3.4 defects per million opportunities. Sigma the Greek letter is defined as a statistical term that refers to the standard deviation of a process about its mean and represents a measure of variation. This term is used to measure defects in the outputs of a process and show how far the process deviates from perfection (Esposto \& Belt, 2009).Six Sigma implementation in any industry is initially very challenging because it requires total commitment from senior management and active role of top management in project selection and resource allocation. It also requires training of some of the people in the industry with the understanding that their role will be fully devoted to implementation of Six Sigma activities (Raisinghani et al., 2005). Prosperous deployment of Six Sigma requires tuning to the culture of the firm and a change in the mind-set of its workforce (Antony \& Banuelas, 2002). Six Sigma cannot be treated as an alone activity. It necessitates attachment to the whole thinking rather than just the usage of few tool and techniques of process improvement. It must be very clear how Six Sigma projects and other activities link to core processes (Neuman \& Cavanagh, 2000). It could be relevant when maintenance of consistency of performance is desirable. It is called when a breakthrough strategy for creativity and innovation is required, where avoidance of non-conformance is of higher priority(Goh, 
2002). Six Sigma is a disciplined approach and its project has been executed through various phases of a scientific model named Define, Measure, Analyse, Improve and Control(DMAIC).This model provides effective utilisation of existing resources, without any extra investments on resources to achieve excellence best in class. After the problem has been defined in Define phase; key process characteristics and root causes are identified and studied in the Measure and Analyze phases. This is followed by the Improve phase where a process is changed for a better or optimization. The Control phase then ensures that the outcomes are sustained ahead of the completion of the project (Goh, 2002; Singh \& Khanduja, 2014).

For the problem of capacity waste in this paper we mainly emphasize on analysis phase of Six Sigma to select the root causes of capacity waste in centre less grinding (CLG) section of selected industry in India. In our study we have identified various capacity waste alternatives in terms of failure/breakdown in CLG section. A proper selection on capacity waste factors has been done and it is a very important issue for automotive companies due to the fact that improperly selected alternatives can depressingly affect the overall performance of a manufacturing system. In addition, the rate of manufacturing systems mostly depends on what kinds of capacity waste arise during production. On the other side, the selection of a critical alternative responsible for capacity waste is time consuming and requiring superior knowledge and experience deeply. So the process to evaluate such critical reasons can be a very complex activity for managers, engineers and also for machine operators. For effective evaluation in such kind of problems the decision making could be a complex task may require a large number of factors to be considered huge data to be analyzed. Where decision making could be a complex task, such problems can be effectively undertaken with multiple attribute decision making (MADM) approach. This approach has provided excellent results in complex decision-making problems in engineering (Zeki Ayă̆ \& Özdemir, 2006; Vats \& Vaish, 2013; Zhang, 2004). MADM utilized a lot of methods in literature which includes TOPSIS (Technique for order preference by similarity to ideal solution) (Chen, 2000; Farsijani et al., 2015), VIKOR (VlseKriterijumska Optimisacija I Kompromisno Resenje) (Opricovic \& Tzeng, 2004; Yadollahi Farsi et al., 2012), and AHP (Analytic hierarchy process) (Chang, 1996; Kahraman et al., 2003), SAW (simple additive weighting) (Chen \& Klein, 1997), etc.

Selection of capacity waste alternatives is a multiple attribute decision making problem in the existence of many quantitative and qualitative parameters/attributes suggested by decision makers. So we decided on analytic hierarchy process (AHP) method because it has been extensively used for selecting the best alternatives (Golden et al., 2003; Saaty, 1990, 2008). These MADM methods are mainly used in crisp decision applications. AHP appears not enough to capture decision maker requirements openly because mainly human judgment on qualitative parameters is always subjective and thus indefinite. To overcome this kind of vagueness in human decisions, Fuzzy set theory could be integrated with AHP. The Fuzzy AHP approach permits a more perfect depiction of the decision making process. Fuzzy AHP approach is outstanding MADM approach and has been applied to various problems ranging from supplier selection(Kahraman et al., 2003), machine tool selection(Zeki Ayağ \& Özdemir, 2006; Durán \& Aguilo, 2008),project selection (Huang et al., 2008),Information technology sector(Lee, Chen, \& Chang, 2008), manufacturing systems (Weck et al., 1997), and many more (Kaviani et al., 2014; Varmazyar \& Nouri, 2014). This study aims to prove the validation of the proposed Fuzzy AHP Approach for selection of critical alternatives for capacity waste on a real life system. This case study was carried out in a leading automotive industry in India. The present study is one of the first efforts to evaluate capacity waste alternatives in Six Sigma analysis phase in Indian automotive sector.

\section{Selection criteria for Evaluation of capacity waste}

Six key parameters have been identified for assessment of the critical capacity waste alternatives in centre less grinding section of an automotive industry in India. The key customary parameters in the model are mined from the brainstorming session with decision makers and reports from existing 
literature(Ayăg, 2007; Nguyen et al., 2014). The parameters for decision making are classified in two categories involving the main parameters and sub category.

\begin{tabular}{lll}
\hline Parameters & Symbol & \multicolumn{1}{c}{ Sub Category } \\
\hline Ease of Maintenance & $\mathrm{C}_{1}$ & $\begin{array}{l}\text { Regular maintenance } \\
\text { Corrective maintenance }\end{array}$ \\
Safety & $\mathrm{C}_{2}$ & $\begin{array}{l}\text { Safety door } \\
\text { Safety training } \\
\end{array}$ \\
& $\mathrm{C}_{3}$ & Fire extinguisher \\
MTBF & $\mathrm{C}_{4}$ & $\begin{array}{l}\text { Failure rate } \\
\text { Up time }\end{array}$ \\
Cost & $\mathrm{C}_{5}$ & $\begin{array}{l}\text { Cost of capacity waste } \\
\text { Cost of breakdown }\end{array}$ \\
Green Effect & & $\begin{array}{l}\text { Friendly Environment } \\
\text { Capacity waste minimization } \\
\text { Less energy consumption } \\
\text { Repair Time }\end{array}$ \\
& $\mathrm{C}_{6}$ & $\begin{array}{l}\text { Time to recover } \\
\text { Active repair time }\end{array}$ \\
\hline
\end{tabular}

\section{Methodology used}

In this study a hybrid approach is used where the AHP and Fuzzy techniques are employed together for capacity waste alternatives selection problem in CLG's. Fig.1 shows the flow chart of proposed methodology used in present study and make clears how the views of the decision makers are quantitatively compiled.

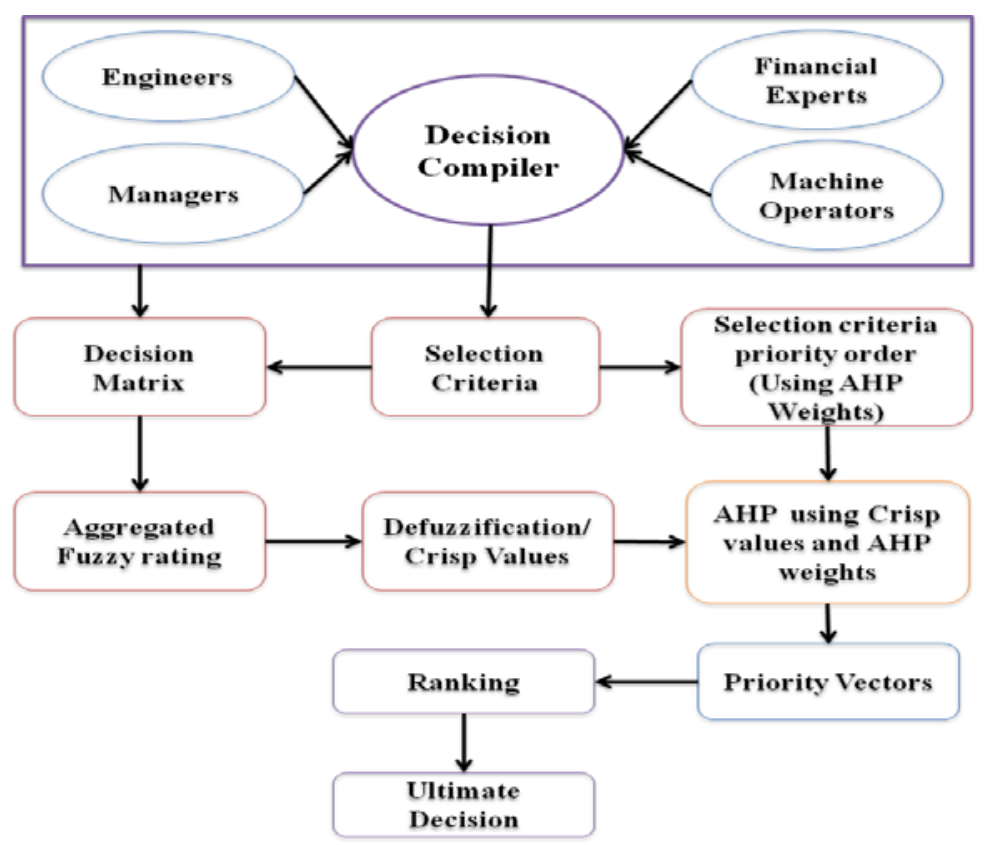

Fig. 1. Flow chart for methodology used.

\subsection{Analytical Hierarchy Process (AHP)}

Analytic hierarchy process was developed by Saaty as a decision making model (Saaty, 1988). It showed how to decide the relative importance of activities in a multi attribute decision making problem. It is one of the widely used decision making approach in industrial problems (Li \& Huang, 2009). The AHP is built on a human inherent capability to construct its views hierarchically. It made pair wise comparison of similar things against a specified norm and review the strength of the importance of one thing over another(Zeki Ayağ \& Özdemir, 2006). For the selection of best alternative the pair wise 
comparisons for each level are performed using a nine point scale (1-9) as shown in Table 1 (Z Ayağ, 2007; Saaty, 1989). That converts the human preferences between offered parameters as equally (1), moderately (3), strongly (5), very strongly (7) or extremely preferred (9). The values thus obtained in scaling process converted into priority values to compare alternatives(Chan, Kumar, Tiwari, Lau, \& Choy, 2008).

\section{Table 1}

Nine point scale used in a pair wise comparison

\begin{tabular}{ll}
\hline Scale importance intensity & Description \\
\hline 1 & Equal importance for both components compared \\
3 & Component A has moderately important compared with component B \\
5 & Component A has strongly important compared with component B \\
7 & Component A has very strongly important compared with component B \\
\hline
\end{tabular}

The basic steps involved in AHP methodology are:

1. Define the problem and its aim.

2. Recognize the measures that influence the performance.

3. Construct the problem into a hierarchy from top to lowest level having goal at top level, criteria, and sub criteria at intermediate level and alternatives at bottom level.

4. Construct a set of pair wise matrix $(n \times n)$ and compare each element in the equivalent level and attune them on relative scale (1-9). This requires $n(n-1)$ judgment, where diagonal elements are equal and the other elements will be the reciprocals of the earlier comparisons.

5. Having made all pair wise comparison, calculations are carried out to find Eigen value, consistency index (CI) consistency ratio (CR) and normalized values for each parameter. The consistency of system can be checked by the consistency ratio $(C R)$ :

$$
C R=\frac{C I}{R I}
$$

where $C I$ is the consistency index which can be obtained as:

$$
C I=\frac{\lambda_{\max }-n}{n-1}
$$

Where $n$ is the matrix size. The random consistency index (R.I.) is the predefined value (Ayağ, 2007; Vaidya \& Kumar, 2006). CR is satisfactory if it does not exceed $10 \%$ then decision is taken based on the normalized values else the judgement matrix is inconsistent; the procedure is repeated till these values lie in a desired scope.

\subsection{Fuzzy Logic}

As the name suggests, Fuzzy logic is the logic of core approach of reasoning which are approximate rather than accurate. The importance of fuzzy logic estimates from the fact that the majority of approaches of human being- reasoning are approximate in nature(Zedeh, 1989).This approach was initiated to carry out the problem where there are no clear edges between the two factors. A fuzzy logic is a class of object with a variety of results of membership. Such type set is branded by a membership function, which assigns to each object a grade of membership within the interval zero and one(Zadeh, 1965). This depicts the degree of significance of an element for being the member of the set. Fuzzy logic approach has proven to be an efficient way for concluding decision problems where the information available is subjective and inexact(Meier et al., 1994). Formally, fuzzy logic is a structured, model free estimator that estimated a function through linguistic variables. A linguistic variable is a variable whose value is denoted in words or sentences in a natural or artificial language(Bonde, 2000). Linguistic variables are a critical aspect of fuzzy logic applications, where general terms such a large, 
medium, and small are each used to capture a range of numerical values. In mathematical applications variables usually take numerical values where as in fuzzy logic applications, the non-numeric are often used(Zadeh, 1997). Fuzzy approach was used for multiple criteria decision making where the stress is on likelihood rather than probability. Different fuzzy numbers are used depending on their situation. In present case we have used trapezoidal fuzzy numbers $\left(b_{1}, b_{2}, b_{3}, b_{4}\right)$ for $\left\{b_{1}, b_{2}, b_{3}, b_{4} \in \mathrm{R} ; b_{1} \leq b_{2} \leq b_{3}\right.$ $\left.\leq b_{4}\right\}$ as in Fig.2.

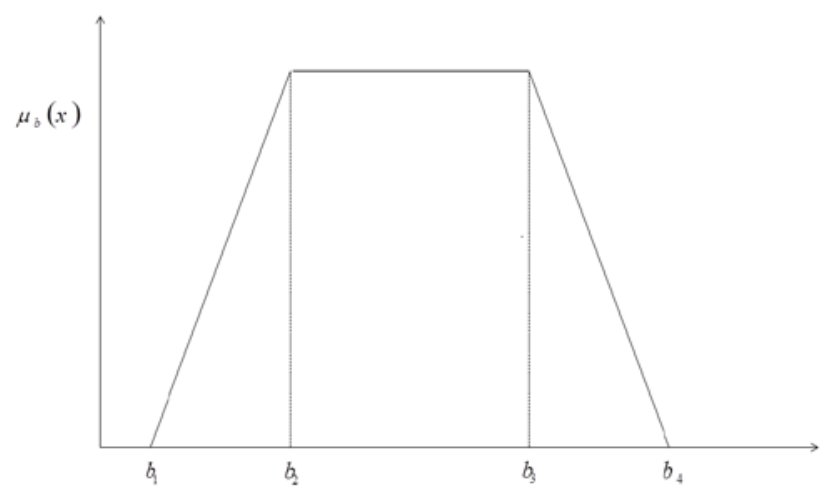

Fig. 2. Trapezoidal fuzzy number

Because of its simplicity and information processing in a fuzzy environment; it is often suitable to work with trapezoidal fuzzy numbers. The membership function $\mu_{b}(\mathrm{x})$ of trapezoidal fuzzy number is defined as

$$
\mu_{b}(\mathrm{x})= \begin{cases}\frac{x-b_{1}}{b_{2}-b_{1}}, & x \in\left[b_{1}, b_{2}\right] \\ 1, & x \in\left[b_{2}, b_{3}\right] \\ \frac{b_{4}-x}{b_{4}-b_{3}}, & x \in\left[b_{3}, b_{4}\right] \\ 0, & \text { otherwise }\end{cases}
$$

\section{Fuzzy AHP Methodology}

This section explains the steps involved in the subjective fuzzy AHP approach for selection of capacity waste alternatives in CLG section of automotive industry. The approach utilizes AHP weights for intercomparison among all criteria followed by fuzzy logic approach with AHP method to obtain critical alternatives. It includes following steps:

Step 1: Computation of AHP weights

As discussed in section 3.1, AHP weights $\left(W_{j}\right)$ are calculated for all capacity waste parameters. This provides the weights of different criteria.

Step 2: Define linguistic terms, relevant membership function and corresponding fuzzy numbers. A set of fuzzy rates is required in order to compare all the alternatives for each criterion. These fuzzy terms are assigned by the decision makers and responsible for intra criterion comparisons of the alternatives.

\section{Step 3: Formation of decision matrix}

Let $p$ be the parameters and $q$ be the alternatives. For $k$ number of decision makers in the proposed model for the aggregated fuzzy rating for $C_{j}$ criterion is represented as $x_{i j k}=\left\{x_{i j k 1}, x_{i j k 2}, x_{i j k 3}, x_{i j k}\right\}$. For $i$ $=1,2 \ldots . . q ; j=1,2 \ldots . . p ; k=1,2 \ldots . k, x_{i j k}$ is calculated as (Shemshadi et al., 2011) 


$$
\left\{\begin{array}{l}
x_{i j 1}=\min _{k}\left\{b_{i j k 1}\right\} \\
x_{i j 2}=\frac{1}{k} \sum b_{i j k 2} \\
x_{i j 3}=\frac{1}{k} \sum b_{i j k 3} \\
x_{i j 4}=\max _{k}\left\{b_{i j k 4}\right\}
\end{array}\right.
$$

Thus the obtained decision matrix $(M)$ is shown as:

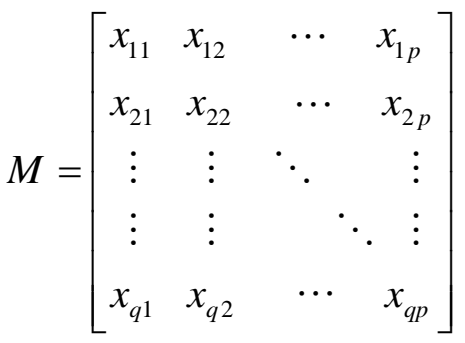

Step 4: Defuzzification

Defuzzification is a process of conversion fuzzy terms to quantified result in fuzzy logic by real valued functions. It is performed to obtain the crisp values (quantifiable result) for each criterion corresponding to each alternative. This provides a quantitative value for the linguistic variables and fuzzy numbers assigned based on the verbal reasoning of the decision makers. Following equation lead to the crisp values:

$$
\begin{aligned}
f_{\mathrm{ij}}=\operatorname{Defuzz}\left(x_{i j}\right)=\frac{\int \mu(x) \cdot x d x}{\int \mu(x) \cdot d x} & \\
= & \frac{\int_{x_{i j 1}}^{x_{i j 2}}\left\{\left(x-x_{i j 1}\right) /\left(x_{i j 2}-x_{i j 1}\right)\right\} \cdot x d x+\int_{x i j 2}^{x_{i j 3}} x d x+\int_{x_{i j 3}}^{x_{i j 4}}\left\{\left(x_{i j 4}-x\right) /\left(x_{i j 4}-x_{i j 3}\right)\right\} \cdot x d x}{\int_{x_{i j 1}}^{x_{i j 2}}\left\{\left(x-x_{i j 1}\right) /\left(x_{i j 2}-x_{i j 1}\right)\right\} d x+\int_{x i j 2}^{x_{i j 3}} d x+\int_{x_{i j 3}}^{x_{i j 4}}\left\{\left(x_{i j 4}-x\right) /\left(x_{i j 4}-x_{i j 3}\right)\right\} \cdot x d x} \\
= & \frac{-x_{i j 1} x_{i j 2}+x_{i j 3} x_{i j 4}+(1 / 3)\left(x_{i j 4}-x_{i j 3}\right)^{2}+(1 / 3)\left(x_{i j 2}-x_{i j 1}\right)^{2}}{-x_{i j 1}-x_{i j 2}-x_{i j 3}+x_{i j 4}}
\end{aligned}
$$

The crisp values, thus obtained are integrated with AHP weights to calculate final ranking using AHP approach as discussed below.

\section{Step 5: Determination of AHP overall priority vectors or AHP index}

Firstly, priority vectors for different evaluation criterion are calculated using the crisp values as demonstrated in Table 2 and Table 3.

\section{Table 2}

Schematic for Capacity waste alternatives and evaluation parameters

\begin{tabular}{lccccc}
\hline & \multicolumn{3}{c}{ Capacity waste alternatives } & & \\
\cline { 2 - 6 } Parameters & Alternative 1 & Alternative 2 & Alternative 3 & Alternative 4 & Alternative 5 \\
\hline Parameter 1 & $\mathrm{X}_{11}$ & $\mathrm{X}_{12}$ & $\mathrm{X}_{13}$ & $\mathrm{X}_{14}$ & $\mathrm{X}_{15}$ \\
Parameter 2 & $\mathrm{X}_{21}$ & $\mathrm{X}_{22}$ & $\mathrm{X}_{23}$ & $\mathrm{X}_{24}$ & $\mathrm{X}_{25}$ \\
Parameter 3 & $\mathrm{X}_{31}$ & $\mathrm{X}_{32}$ & $\mathrm{X}_{33}$ & $\mathrm{X}_{34}$ & $\mathrm{X}_{35}$ \\
Parameter 4 & $\mathrm{X}_{41}$ & $\mathrm{X}_{42}$ & $\mathrm{X}_{43}$ & $\mathrm{X}_{44}$ & $\mathrm{X}_{45}$ \\
Parameter 5 & $\mathrm{X}_{51}$ & $\mathrm{X}_{52}$ & $\mathrm{X}_{53}$ & $\mathrm{X}_{54}$ & $\mathrm{X}_{55}$ \\
Parameter 6 & $\mathrm{X}_{61}$ & $\mathrm{X}_{62}$ & $\mathrm{X}_{63}$ & $\mathrm{X}_{64}$ & $\mathrm{X}_{65}$ \\
\hline
\end{tabular}


Thereafter, the sum product of priority vectors gives the overall priority vector for each parameter. We have named it as the AHP index as it provides the factors responsible for capacity waste in contrast to various evaluation criteria. The alternative with highest value of AHP index is preferred.

Table 3

Pair wise Comparison matrix for capacity waste alternatives for parameter 1 (from Table 2)

\begin{tabular}{lllllc}
\hline & Alternative 1 & Alternative 2 & Alternative 3 & Alternative 4 & Alternative 5 \\
\hline Alternative 1 & 1 & $\mathrm{X}_{11} / \mathrm{X}_{12}$ & $\mathrm{X}_{11} / \mathrm{X}_{13}$ & $\mathrm{X}_{11} / \mathrm{X}_{14}$ & $\mathrm{X}_{11} / \mathrm{X}_{15}$ \\
Alternative 2 & $\mathrm{X}_{12} / \mathrm{X}_{11}$ & 1 & $\mathrm{X}_{12} / \mathrm{X}_{13}$ & $\mathrm{X}_{12} / \mathrm{X}_{14}$ & $\mathrm{X}_{12} / \mathrm{X}_{15}$ \\
Alternative 3 & $\mathrm{X}_{13} / \mathrm{X}_{11}$ & $\mathrm{X}_{13} / \mathrm{X}_{12}$ & 1 & $\mathrm{X}_{13} / \mathrm{X}_{14}$ & $\mathrm{X}_{13} / \mathrm{X}_{15}$ \\
Alternative 4 & $\mathrm{X}_{14} / \mathrm{X}_{11}$ & $\mathrm{X}_{14} / \mathrm{X}_{12}$ & $\mathrm{X}_{14} / \mathrm{X}_{13}$ & 1 & $\mathrm{X}_{14} / \mathrm{X}_{15}$ \\
Alternative 5 & $\mathrm{X}_{15} / \mathrm{X}_{11}$ & $\mathrm{X}_{15} / \mathrm{X}_{12}$ & $\mathrm{X}_{15} / \mathrm{X}_{13}$ & $\mathrm{X}_{15} / \mathrm{X}_{14}$ & 1 \\
\hline
\end{tabular}

\section{Results and Discussion}

In automotive firms, it is quite difficult to find out exact factors of capacity waste due to which the available resources are underutilized. Proper capacity waste management inside the industry might be very helpful in deciding the performance of the industry. Efficient capacity utilization is always important for the industry because under utilization always results in lower production, excessive delays, and ultimately leads to poor productivity levels. In current study, in brainstorming sessions with decision makers like, production manager, engineers, machine operators and financial experts, etc.; it is concluded that selection of the critical capacity waste alternatives in CLG section depends on six criteria as discussed in Section 2, which carried a meaningful impact on selection of alternatives. . It is closely observed that impact of these parameters differ from shop floor of industry to industry. As these parameters are identified, the next step is to prioritize these parameters, as to which of these have extra impact on the identified capacity waste reasons. AHP approach is used to prioritize these parameters and in order to compare these distinct parameters, numeric priority values are assigned to the parameters on a scale of 1-9 and a set of pair wise matrix is made to carry out comparison. Table 4 shows the relative decision matrix formed on the basis of pair-wise comparison and the weights are calculated for considered criteria. MTBF comes out as the most dominant parameter for the selection of these capacity waste alternatives; while green effect impacted as least dominant parameter.

\section{Table 4}

Subjective weights of the evaluation criteria calculated using AHP

\begin{tabular}{llllllll}
\hline Parameters & $\mathrm{C}_{1}$ & $\mathrm{C}_{2}$ & $\mathrm{C}_{3}$ & $\mathrm{C}_{4}$ & $\mathrm{C}_{5}$ & Weights & Rank \\
\hline Ease of Maintenance $\left(\mathrm{C}_{1}\right)$ & 1 & 5 & 0.11 & 0.14 & 5 & 0.0768 & 4 \\
Safety $\left(\mathrm{C}_{2}\right)$ & 0.20 & 1 & 0.11 & 0.14 & 3 & 0.0381 & 5 \\
MTBF($\left(\mathrm{C}_{3}\right)$ & 9 & 9 & 1 & 9 & 9 & 0.4945 & 1 \\
Cost $\left(\mathrm{C}_{4}\right)$ & 7 & 7 & 0.11 & 1 & 7 & 0.2187 & 2 \\
Green Effect $\left(\mathrm{C}_{5}\right)$ & 0.20 & 0.33 & 0.11 & 0.14 & 1 & 0.0239 & 6 \\
Repair Time $\left(\mathrm{C}_{6}\right)$ & 7 & 7 & 0.11 & 0.14 & 7 & 0.1478 & 3 \\
\hline
\end{tabular}

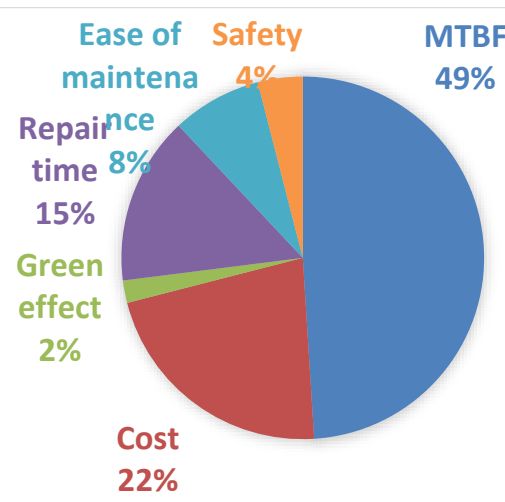

Fig. 3. Contribution of all major parameters towards the selection of capacity waste alternatives in CLG's

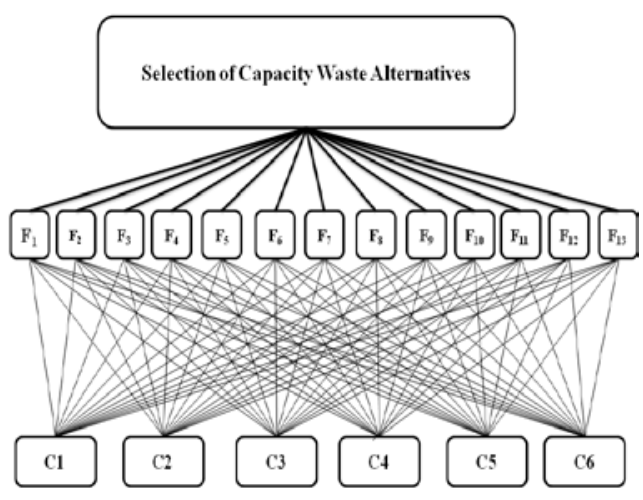

Fig. 4. The hierarchical structure for the selection of the capacity waste alternatives in CLG's 
Fig. 3 shows the contribution of all governing parameters towards the selection of capacity waste alternatives. The hierarchical structure for the selection of capacity waste alternatives in CLG's is shown in Fig. 4. Level 1 specifies our goal on selection of the capacity waste alternatives that have to be selected from the identified thirteen important factors of capacity waste indicated in level 2. Level 3 demonstrates that the Capacity waste alternatives are fully interdependent on critical selection parameters, which shows the complexity of the problem. Moreover, this is a time consuming process and significant knowledge of both technological as well as economic aspects is needed in this case.

Table 5

Linguistic variables and corresponding fuzzy numbers

\begin{tabular}{ll}
\hline Linguistic Variable & Fuzzy number \\
\hline Extremely High (EH) & $(0.8,0.9,1.0,1.0)$ \\
Very high (VH) & $(0.7,0.8,0.8,0.9)$ \\
High (H) & $(0.5,0.6,0.7,0.8)$ \\
Above average (AA) & $(0.4,0.5,0.5,0.6)$ \\
Average (A) & $(0.2,0.3,0.4,0.5)$ \\
Very low (VL) & $(0.1,0.2,0.2,0.3)$ \\
Extremely low (EL) & $(0.0,0.0,0.1,0.2)$ \\
\hline
\end{tabular}

\section{Table 6}

Linguistic decision matrix of capacity waste alternatives for all evaluation criteria

\begin{tabular}{|c|c|c|c|c|c|c|}
\hline \multirow[t]{2}{*}{ Capacity Waste Factors (Alternatives) } & \multicolumn{6}{|c|}{ Evaluation Criteria(Parameters) } \\
\hline & C1 & C2 & C3 & C4 & C5 & C6 \\
\hline Conveyor Malfunction( $\left.\mathrm{F}_{1}\right)$ & EL & VL & EL & $\mathrm{EH}$ & $\mathrm{VH}$ & $\mathrm{EH}$ \\
\hline Loader Failure $\left(\mathrm{F}_{2}\right)$ & VL & A & VL & $\mathrm{VH}$ & VH & $\mathrm{EH}$ \\
\hline Gear box fault $\left(\mathrm{F}_{3}\right)$ & A & VL & A & $\mathrm{H}$ & AA & $\mathrm{H}$ \\
\hline Coolant pump Malfunction $\left(\mathrm{F}_{4}\right)$ & EL & A & VL & $\mathrm{VH}$ & $\mathrm{VH}$ & $\mathrm{EH}$ \\
\hline Hydraulic motor not working $\left(\mathrm{F}_{5}\right)$ & A & A & $\mathrm{AA}$ & AA & A & VH \\
\hline Hydraulic oil leakage $\left(\mathrm{F}_{6}\right)$ & VL & VL & VL & $\mathrm{VH}$ & $\mathrm{H}$ & $\mathrm{EH}$ \\
\hline Slide failure $\left(F_{7}\right)$ & EL & VL & VL & $\mathrm{EH}$ & VH & $\mathrm{EH}$ \\
\hline Spindle jam $\left(\mathrm{F}_{8}\right)$ & VL & A & VL & $\mathrm{VH}$ & VH & $\mathrm{EH}$ \\
\hline CWD unit fault $\left(\mathrm{F}_{9}\right)$ & VL & EL & VL & $\mathrm{EH}$ & $\mathrm{H}$ & $\mathrm{EH}$ \\
\hline Electrical faults $\left(\mathrm{F}_{10}\right)$ & VL & A & VL & $\mathrm{H}$ & VH & VH \\
\hline Sensor faults $\left(F_{11}\right)$ & $\mathrm{H}$ & $\mathrm{H}$ & $\mathrm{H}$ & A & VL & VL \\
\hline Grinding wheel Fault $\left(\mathrm{F}_{12}\right)$ & $\mathrm{A}$ & AA & $\mathrm{AA}$ & AA & $\mathrm{H}$ & $\mathrm{H}$ \\
\hline Improper lubrication $\left(\mathrm{F}_{13}\right)$ & $\mathrm{VH}$ & AA & $\mathrm{AA}$ & VL & $\mathrm{VH}$ & EL \\
\hline
\end{tabular}

Further next, on the decisions of decision makers for comparison of all alternatives for each parameter, fuzzy hypothesis analysis is carried out. Linguistic variables were used for this problem, these variables further converted into corresponding fuzzy numbers. Table 5 shows these linguistic variables and their corresponding fuzzy numbers. The highest range is termed extremely high $(\mathrm{EH})$ and the least is termed as extremely low (EL). During our brainstorming session with decision makers the linguistic decision matrix was filled as shown in Table 6. Here a single decision matrix has been formed rather than having a separate decision matrix for each decision maker (as per discussion with decision makers). Further, fuzzy values thus obtained are finally changed into crisp values using Equation 7. Calculated crisp values obtained from aggregated fuzzy ratings shown in Table 7 . The crisp values thus obtained are utilized to calculate the priority vectors for each parameter with respect to distinct alternative. Table 8 shows corresponding rank indices and ranks for the capacity waste alternatives in CLG section. Our analysis shows that conveyor malfunction is the prime factor responsible for capacity waste in CLG section. Other main reasons for capacity waste are, CWD unit fault, slide failure, electrical faults and loader failure respectively (refer Table 8). It is also observed that grinding wheel fault is having least effect on capacity waste of this section. Improper lubrication and sensor faults are also rarely responsible for failure. We found that our results are in good agreement with perceptions of automotive company. 
Table 7

Calculated crisp values for assigned fuzzy rates

\begin{tabular}{lcccccc}
\hline Capacity Waste Factors (Alternatives) & \multicolumn{7}{c}{ Evaluation Criteria(Parameters) } \\
\cline { 2 - 7 } & $\mathrm{C} 1$ & $\mathrm{C} 2$ & $\mathrm{C} 3$ & $\mathrm{C} 4$ & $\mathrm{C} 5$ & $\mathrm{C} 6$ \\
\hline $\mathrm{F}_{1}$ & 0.077778 & 0.383333 & 0.177778 & 0.944444 & 0.983333 & 0.944444 \\
$\mathrm{~F}_{2}$ & 0.233333 & 0.366667 & 0.233333 & 0.833333 & 0.833333 & 0.944444 \\
$\mathrm{~F}_{3}$ & 0.366667 & 0.233333 & 0.366667 & 0.666667 & 0.533333 & 0.666667 \\
$\mathrm{~F}_{4}$ & 0.077778 & 0.366667 & 0.233333 & 0.833333 & 0.833333 & 0.944444 \\
$\mathrm{~F}_{5}$ & 0.366667 & 0.366667 & 0.533333 & 0.533333 & 0.366667 & 0.833333 \\
$\mathrm{~F}_{6}$ & 0.233333 & 0.233333 & 0.233333 & 0.833333 & 0.666667 & 0.944444 \\
$\mathrm{~F}_{7}$ & 0.077778 & 0.233333 & 0.233333 & 0.944444 & 0.833333 & 0.944444 \\
$\mathrm{~F}_{8}$ & 0.233333 & 0.366667 & 0.233333 & 0.833333 & 0.833333 & 0.944444 \\
$\mathrm{~F}_{9}$ & 0.233333 & 0.077778 & 0.233333 & 0.944444 & 0.666667 & 0.944444 \\
$\mathrm{~F}_{10}$ & 0.233333 & 0.366667 & 0.233333 & 0.666667 & 0.833333 & 0.833333 \\
$\mathrm{~F}_{11}$ & 0.666667 & 0.666667 & 0.666667 & 0.366667 & 0.233333 & 0.233333 \\
$\mathrm{~F}_{12}$ & 0.366667 & 0.533333 & 0.533333 & 0.533333 & 0.666667 & 0.666667 \\
$\mathrm{~F}_{13}$ & 0.833333 & 0.533333 & 0.533333 & 0.233333 & 0.833333 & 0.0777778 \\
\hline
\end{tabular}

Table 8

Calculated AHP ranking

\begin{tabular}{lllllllll}
\hline Alternatives & C1 & C2 & C3 & C4 & C5 & C6 & $\begin{array}{l}\text { AHP } \\
\text { Index }\end{array}$ & $\begin{array}{l}\text { AHP } \\
\text { Rank }\end{array}$ \\
\hline AHP Weights & 0.0768 & 0.0382 & 0.4945 & 0.2187 & 0.0240 & 0.1478 & & \\
Conveyor Malfunction & 0.1814 & 0.0553 & 0.1237 & 0.1030 & 0.1079 & 0.0952 & 0.1304 & 1 \\
Loader Failure & 0.0605 & 0.0578 & 0.0942 & 0.0909 & 0.0914 & 0.0952 & 0.0905 & 5 \\
Gear box fault & 0.0385 & 0.0908 & 0.0600 & 0.0727 & 0.0585 & 0.0672 & 0.0687 & 9 \\
Coolant pump Malfunction & 0.1814 & 0.0578 & 0.0942 & 0.0909 & 0.0914 & 0.0952 & 0.0781 & 7 \\
Hydraulic motor not working & 0.0385 & 0.0578 & 0.0412 & 0.0582 & 0.0402 & 0.0840 & 0.0728 & 8 \\
Hydraulic oil leakage & 0.0605 & 0.0908 & 0.0942 & 0.0909 & 0.0731 & 0.0952 & 0.0645 & 10 \\
Slide failure & 0.1814 & 0.0908 & 0.0942 & 0.1030 & 0.0914 & 0.0952 & 0.0908 & 3 \\
Spindle jam & 0.0605 & 0.0578 & 0.0942 & 0.0909 & 0.0914 & 0.0952 & 0.0897 & 6 \\
CWD unit fault & 0.0605 & 0.2723 & 0.0942 & 0.1030 & 0.0731 & 0.0952 & 0.0930 & 2 \\
Electrical faults & 0.0605 & 0.0578 & 0.0942 & 0.0727 & 0.0914 & 0.0840 & 0.0907 & 4 \\
Sensor faults & 0.0212 & 0.0318 & 0.0330 & 0.0400 & 0.0256 & 0.0235 & 0.0497 & 11 \\
Grinding wheel Fault & 0.0385 & 0.0397 & 0.0412 & 0.0582 & 0.0731 & 0.0672 & 0.0386 & 13 \\
Improper lubrication & 0.0169 & 0.0397 & 0.0412 & 0.0255 & 0.0914 & 0.0078 & 0.0423 & 12 \\
\hline
\end{tabular}

\section{Conclusions}

In this study, a tactical approach has been used to evaluate capacity waste alternatives in CLG section of an automotive industry using Fuzzy AHP methodology. Trapezoidal fuzzy numbers were used with conventional AHP in turn to improve the degree of decisions of decision makers. Analytic Hierarchy Process (AHP) method is used to calculate weights of all persuasive parameters for selection of the capacity waste alternatives. MTBF has been found to be the most serious and green effect as least critical parameter. The number of alternatives is limited to thirteen because these are mainly responsible for considerable capacity waste. Further priority order of critical factors of capacity waste in CLG section is determined using fuzzy AHP approach. Conveyor malfunction is found to be the critical factor responsible for capacity waste in CLG section. This study explores the feasibility of combination of fuzzy MADM with AHP in Six Sigma analysis phase as a valuable tool in Six Sigma analysis for selection of the Capacity waste alternatives.

\section{References}

Alp, O., \& Tan, T. (2008). Tactical capacity management under capacity flexibility. IIE Transactions, 40(3), 221-237.

Antony, J. (2004). Some pros and cons of Six Sigma: an academic perspective. The TQM Magazine, 16(4), 303-306. 
Antony, J., \& Banuelas, R. (2002). Key ingredients for the effective implementation of Six Sigma program. Measuring Business Excellence, 6(4), 20-27.

Antony, J., \& Fergusson, C. (2004). Six Sigma in the software industry: results from a pilot study. Managerial Auditing Journal, 19(8), 1025-1032.

Ayağ, Z. (2007). A hybrid approach to machine-tool selection through AHP and simulation. International Journal of Production Research, 45(9), 2029-2050.

Ayağ, Z., \& Özdemir, R. G. (2006). A fuzzy AHP approach to evaluating machine tool alternatives. Journal of Intelligent Manufacturing, 17(2), 179-190.

Baghestani, H. (2008). Predicting capacity utilization: Federal Reserve vs time-series models. Journal of Economics and Finance, 32(1), 47-57.

Bonde, A. (2000). Fuzzy logic basics. SiteTerrific Web Solutions. GTE, 2194.

Chan, F. T., Kumar, N., Tiwari, M., Lau, H., \& Choy, K. (2008). Global supplier selection: a fuzzyAHP approach. International Journal of Production Research, 46(14), 3825-3857.

Chang, D.-Y. (1996). Applications of the extent analysis method on fuzzy AHP. European journal of operational research, 95(3), 649-655.

Chen, C.-b., \& Klein, C. M. (1997). An efficient approach to solving fuzzy MADM problems. Fuzzy Sets and Systems, 88(1), 51-67.

Chen, C.-T. (2000). Extensions of the TOPSIS for group decision-making under fuzzy environment. Fuzzy sets and systems, 114(1), 1-9.

Coronado, R. B., \& Antony, J. (2002). Critical success factors for the successful implementation of six sigma projects in organisations. The TQM magazine, 14(2), 92-99.

Dedhia, N. S. (2005). Six sigma basics. Total Quality Management \& Business Excellence, 16(5), 567574.

Durán, O., \& Aguilo, J. (2008). Computer-aided machine-tool selection based on a Fuzzy-AHP approach. Expert Systems with Applications, 34(3), 1787-1794.

Eckes, G. (2002). The Six Sigma revolution: How General Electric and others turned process into profits: John Wiley \& Sons.

Esposto, F., \& Belt, M. B. (2009). Six sigma basics. USC Consulting group, link: six-sigma-basics41. $p d f$.

Farsijani, H., Nikabadi, M., \& Amirimoghadam, H. (2015). Six sigma project selections using fuzzy network-analysis and fuzzy MADM. Decision Science Letters, 4(1), 87-96.

Felthoven, R. G., Horrace, W. C., \& Schnier, K. E. (2009). Estimating heterogeneous capacity and capacity utilization in a multi-species fishery. Journal of Productivity Analysis, 32(3), 173-189.

Goh, T. N. (2002). A strategic assessment of Six Sigma. Quality and Reliability Engineering International, 18(5), 403-410.

Golden, B. L., Wasil, E. A., \& Harker, P. T. (2003). Analytic hierarchy process: Springer.

Hahn, G. J., Hill, W. J., Hoerl, R. W., \& Zinkgraf, S. A. (1999). The impact of Six Sigma improvement-a glimpse into the future of statistics. The American Statistician, 53(3), 208-215.

Hammesfahr, R. J., Pope, J. A., \& Ardalan, A. (1993). Strategic planning for production capacity. International Journal of Operations \& Production Management, 13(5), 41-53.

Huang, C.-C., Chu, P.-Y., \& Chiang, Y.-H. (2008). A fuzzy AHP application in government-sponsored R\&D project selection. Omega, 36(6), 1038-1052.

Kahraman, C., Cebeci, U., \& Ulukan, Z. (2003). Multi-criteria supplier selection using fuzzy AHP. Logistics Information Management, 16(6), 382-394.

Kaviani, M., Abbasi, M., Yusefi, M., \& Zareinejad, M. (2014). Prioritizing operation strategies of companies using fuzzy AHP and importance-performance matrix. Decision Science Letters, 3(3), 353-358.

Lee, A. H., Chen, W.-C., \& Chang, C.-J. (2008). A fuzzy AHP and BSC approach for evaluating performance of IT department in the manufacturing industry in Taiwan. Expert systems with applications, 34(1), 96-107.

Li, T.-S., \& Huang, H.-H. (2009). Applying TRIZ and Fuzzy AHP to develop innovative design for automated manufacturing systems. Expert systems with applications, 36(4), 8302-8312. 
Meier, W., Weber, R., \& Zimmermann, H.-J. (1994). Fuzzy data analysis-methods and industrial applications. Fuzzy sets and systems, 61(1), 19-28.

Neuman, R. P., \& Cavanagh, R. (2000). The six sigma way: How GE, Motorola, and other top companies are honing their performance: McGraw Hill Professional.

Nguyen, H.-T., Dawal, S. Z. M., Nukman, Y., \& Aoyama, H. (2014). A hybrid approach for fuzzy multi-attribute decision making in machine tool selection with consideration of the interactions of attributes. Expert Systems with Applications, 41(6), 3078-3090.

Opricovic, S., \& Tzeng, G.-H. (2004). Compromise solution by MCDM methods: A comparative analysis of VIKOR and TOPSIS. European Journal of Operational Research, 156(2), 445-455.

Orr, S. (1999). The role of capacity management in manufacturing strategy: experiences from the Australian wine industry. Technology Analysis \& Strategic Management, 11(1), 45-53.

Raisinghani, M. S., Ette, H., Pierce, R., Cannon, G., \& Daripaly, P. (2005). Six Sigma: concepts, tools, and applications. Industrial Management \& Data Systems, 105(4), 491-505.

Saaty, T. L. (1988). What is the analytic hierarchy process? : Springer.

Saaty, T. L. (1989). Group decision making and the AHP The Analytic Hierarchy Process (pp. 59-67): Springer.

Saaty, T. L. (1990). How to make a decision: the analytic hierarchy process. European journal of operational research, 48(1), 9-26.

Saaty, T. L. (2008). Decision making with the analytic hierarchy process. International journal of services sciences, 1(1), 83-98.

Sahoo, B. K., \& Tone, K. (2009). Decomposing capacity utilization in data envelopment analysis: An application to banks in India. European Journal of Operational Research, 195(2), 575-594.

Shemshadi, A., Shirazi, H., Toreihi, M., \& Tarokh, M. J. (2011). A fuzzy VIKOR method for supplier selection based on entropy measure for objective weighting. Expert Systems with Applications, 38(10), 12160-12167.

Singh, B. J., \& Khanduja, D. (2014). Perspectives of control phase to manage Six Sigma implements: an empirical study. International Journal of Business Excellence, 7(1), 88-111.

Snee, R. D. (2004). Six-Sigma: the evolution of 100 years of business improvement methodology. International Journal of Six Sigma and Competitive Advantage, 1(1), 4-20.

Vaidya, O. S., \& Kumar, S. (2006). Analytic hierarchy process: An overview of applications. European Journal of operational research, 169(1), 1-29.

Varmazyar, M., \& Nouri, B. (2014). A fuzzy AHP approach for employee recruitment. Decision Science Letters, 3(1), 27-36.

Vats, G., \& Vaish, R. (2013). Piezoelectric material selection for transducers under fuzzy environment. Journal of Advanced Ceramics, 2(2), 141-148.

Weck, M., Klocke, F., Schell, H., \& Rüenauver, E. (1997). Evaluating alternative production cycles using the extended fuzzy AHP method. European Journal of Operational Research, 100(2), 351366.

Yadollahi Farsi, J., Siahkali Moradi, J., \& Jamali, B. (2012). Which product would be chosen? A fuzzy VIKOR method for evaluation and selection of products in terms of customers' point of view; Case study: Iranian cell phone market. Decision Science Letters, 1(1), 23-32.

Zadeh, L. A. (1965). Fuzzy sets. Information and control, 8(3), 338-353.

Zadeh, L. A. (1997). Toward a theory of fuzzy information granulation and its centrality in human reasoning and fuzzy logic. Fuzzy sets and systems, 90(2), 111-127.

Zedeh, L. (1989). Knowledge representation in fuzzy logic. Knowledge and Data Engineering, IEEE Transactions on, 1(1), 89-100.

Zhang, W. (2004). Handover decision using fuzzy MADM in heterogeneous networks. Paper presented at the Wireless Communications and Networking Conference, 2004. WCNC. 2004 IEEE. 